\title{
Inclusão de silagem de rama de mandioca em substituição à pastagem na alimentação de vacas em lactação: produção, qualidade do leite e da gordura
}

\section{RESUMO}

Avaliou-se o efeito da substituição da pastagem pela silagem de rama de mandioca (SRM) sobre a produção e constituintes do leite e sobre a qualidade da gordura do leite de vacas da raça Holandesa. O delineamento experimental utilizado foi um duplo quadrado latino $4 \times 4$, e para o fator níveis de suplementação, foi usado regressão. A dieta-controle foi $50 \%$ concentrado e $50 \%$ volumoso, e as proporções de substituição do volumoso foram $0,20,40$ e $60 \%$ com base na matéria seca. Todas as dietas eram isoprotéicas. Foram analisados: produção de leite (PL), PL corrigida a 4\% (PLC), acidez, gordura (\%), densidade, proteína, lactose, sólidos totais, contagem de células somáticas (CCS), ureia e perfil dos ácidos graxos da gordura do leite. Houve efeito linear decrescente da substituição do volumoso pela SRM sobre a PL, PLC e ureia no leite, e efeito $(\mathrm{P}<0,05)$ linear crescente sobre a concentração de ácido gama linolênico e ácido palmítico. A acidez, densidade, proteína, gordura, lactose, sólidos totais, CCS e demais ácidos graxos da gordura do leite permaneceram inalterados com a incorporação da SRM na dieta.

Palavras-chave: gado de leite, subproduto, produção de leite, perfil de ácidos graxos

\begin{abstract}
The effect of a partial substitution of pasture for cassava foliage silage (CFS) on milk production and composition on fat quality of Holstein cow milk was studied using a replicated $4 X 4$ Latin square design with four treatments. Regression was used for the comparison of nutrition levels. The control diet contained 50\% pasture and 50\% concentrate on a dry matter basis. The substitution levels of pasture for CFS were 0, 20, 40, or $60 \%$ of the forage dry matter. All diets were isonitrogenous. The analyzed parameters were: milk production (MP); 4\% fat-corrected milk production (FCM); acidity; density; concentrations of fat, protein, lactose, urea, and total solids; somatic cell counts (SCC), and milk fatty acids profile. There was a linear decrease effect $(P<0.05)$ in MP, FCM, and urea content with increasing levels of CFS in the diet. Concentrations of gamma linolenic and palmitic acids in milk fat linearly increased $(P<0.05)$ with higher proportions of CFS in the diet. Other contents of milk fatty acids remained similar among treatments as well as acidity; density; concentrations of protein, fat, lactose, and total solids; and SCC.
\end{abstract}

Keywords: dairy cattle, by-product, milk production, fatty acid profile

Recebido em 23 de novembro de 2007

Aceito em 26 de novembro de 2008

E-mail: elisacm@ufrpe.br

Apoio: $\mathrm{CNPq}$ - Projeto Universal - processo no. 477.456/01-4 


\section{INTRODUÇÃO}

Os sistemas de criação de gado de leite com base na utilização adequada de pastagens podem diminuir os custos de produção de leite, reduzindo o uso de alimentos concentrados e a mão-de-obra e os investimentos em instalações, em relação aos sistemas que se baseiam em confinamento (Vilela et al., 2005; Vilela et al., 2007).

As altas temperaturas favorecem $o$ desenvolvimento das forrageiras tropicais, mas também causam aumento na atividade metabólica da planta, levando ao decréscimo nos conteúdos de nitratos, proteína e carboidratos solúveis e aumento nos componentes da parede celular, podendo, dessa forma, resultar em declínio acelerado na qualidade (Van Soest, 1994; Gonçalves et al., 2002).

Vilela et al. (2007), ao trabalharem com vacas da raça Holandesa, mantidas em pastagem de capim coast-cross e suplementadas com 3 ou $6 \mathrm{~kg}$ de concentrado/vaca/dia, obtiveram 15,5 e $19,1 \mathrm{~kg}$ de leite/vaca/dia. A persistência na lactação foi maior quando as vacas receberam $6 \mathrm{~kg}$ de concentrado em comparação com as que receberam $3 \mathrm{~kg}$.

Os estudos realizados com suplementação volumosa de vacas leiteiras em pasto têm se restringido à suplementação no período da seca. Essa estratégia é bem conhecida, uma vez que nesse período as pastagens cessam de crescer ou diminuem seu crescimento por diversas razões, entre elas a falta de umidade, menor intensidade luminosa e fatores ligados à própria fisiologia da planta forrageira. Todavia, no Norte do Paraná, durante o verão, tem-se observado que a distribuição das chuvas é irregular, ocasionando "veranicos" por períodos prolongados. Neste caso, têm-se todas as condições favoráveis para o crescimento das pastagens tropicais, mas falta água. Para contornar essa situação, pode-se lançar mão da irrigação ou da suplementação volumosa por períodos curtos durante o verão. Em tais circunstâncias, buscam-se fontes suplementares menos onerosas para formulação de rações para os bovinos. Os resíduos da mandioca, tradicionalmente cultivada na maior parte do país, constituem-se em alternativas para alimentação de vacas leiteiras no período de entressafra, isto é, durante o período seco. A rama de mandioca pode ser utilizada como forragem verde e como forragem conservada na forma de feno ou de silagem. No entanto, pouco se conhece, efetivamente, sobre o seu potencial para essa finalidade (Santos et al., 2001).

A rama de mandioca corresponde ao terço superior da planta acima do solo, mais enfolhado e, consequentemente, mais rico em proteína (Carvalho e Kato, 1987). A parte aérea da mandioca é, sistematicamente, perdida no campo durante a colheita das raízes. Estima-se que aproximadamente 14 a 16 milhões de toneladas de parte aérea são deixadas no campo, a cada ano. Esse material poderia ser transformado em produtos de uso animal (Carvalho e Kato, 1987; Euclides et al., 1988) e estudos realizados com a conservação da rama de mandioca mostram que ela pode ser bem conservada na forma de silagem (Faustino et al., 2003; Modesto et al., 2004).

A nutrição animal pode surtir efeitos na qualidade do leite, ou seja, a dieta pode influenciar as proporções dos principais componentes do leite, como a gordura, a proteína e a lactose. A proteína é determinante para o rendimento da produção de vários produtos lácteos. A descoberta da ação positiva à saúde de ácidos graxos, como o ácido linoléico conjugado (CLA) existente no leite, faz com que este seja reconhecido como um alimento funcional (ou nutracêutico). Essa categoria de alimento promete não só nutrir, como prevenir ou combater doenças e melhorar a saúde do consumidor. Neste caso há a valorização dos produtos lácteos (Medeiros et al., 2001).

O objetivo deste trabalho foi estudar o efeito da substituição da pastagem de Cynodon por SRM na alimentação de vacas em lactação sobre a produção e a qualidade da gordura do leite.

\section{MATERIAL E MÉTODOS}

O experimento foi realizado em uma área experimental constituída de dois piquetes de $0,50 \mathrm{ha}$, formados predominantemente por gramíneas do gênero Cynodon dactylon (L.) Pers. cv coastcross, localizados nas imediações das instalações para manejo e alimentação dos animais. Foram empregadas oito vacas da raça Holandesa, multíparas, com média de $100 \pm 21$ 
dias em lactação e $530 \pm 58 \mathrm{~kg}$ de peso corporal (PC).

Os tratamentos basearam-se na inclusão gradativa de SRM à dieta dos animais em lactação. As rações totais foram balanceadas com base nas exigências de energia líquida para mantença e lactação de um animal padrão, com $550 \mathrm{~kg}$ de peso vivo e produção esperada de $25 \mathrm{~kg}$ de leite com $4 \%$ de gordura de acordo com o NRC (Nutrient..., 1998). As rações finais foram isoproteicas para um consumo de pasto que se pretendeu uma relação volumoso:concentrado 50:50 com base na MS. A partir desse pressuposto, projetou-se a substituição gradativa do esperado consumo de pasto pela dieta de SRM. Dessa forma, foram avaliados os tratamentos: T0, constituido por $50 \%$ de pastagem $+50 \%$ de concentrado; T20, $40 \%$ de pastagem e $10 \%$ de SRM $+50 \%$ de concentrado; T40, $30 \%$ de pastagem e $20 \%$ de SRM $+50 \%$ de concentrado; e T60, 20\% de pastagem e 30\% de $\mathrm{SRM}+50 \%$ de concentrado. A proporção esperada dos alimentos na ração total, bem como a composição químico-bromatológica projetada para dieta total são mostradas na Tab. 1 .

O experimento constou de quatro períodos experimentais de 21 dias de duração, sendo os 10 primeiros destinados à adaptação dos animais. Durante o experimento, os animais, mantidos nos piquetes experimentais, foram submetidos a todos os tratamentos. Diariamente, foram conduzidos à sala de ordenha, às $8 \mathrm{~h}$ e às $15 \mathrm{~h}$, para os procedimentos de ordenha e, em seguida, ao estábulo para o fornecimento do suplemento, que foi oferecido à vontade, em quantidades suficientes para permitir sobras aproximadas de $10-15 \%$, em um período de consumo de aproximadamente duas horas, quando os animais eram novamente conduzidos aos piquetes.

Tabela 1. Porcentagem dos ingredientes com base na matéria seca e composição química das rações usadas para vacas em lactação, segundo a proporção de substituição do pasto pela silagem de rama de mandioca

\begin{tabular}{|c|c|c|c|c|}
\hline \multirow{2}{*}{ Alimento } & \multicolumn{4}{|c|}{ Proporção de substituição } \\
\hline & $0 \%$ & $20 \%$ & $40 \%$ & $60 \%$ \\
\hline & \multicolumn{4}{|c|}{$\mathrm{kg}$ de MS } \\
\hline Pasto de Cynodon ${ }^{1}$ & \multicolumn{4}{|c|}{ Ad libitum } \\
\hline Silagem de rama de mandioca & 0,00 & 1,75 & 3,5 & 5,25 \\
\hline Caroço de algodão & 1,00 & 1,00 & 1,00 & 1,00 \\
\hline Casca de soja & 5,90 & 6,25 & 6,59 & 6,93 \\
\hline Farelo de soja & 1,71 & 1,36 & 1,02 & 0,68 \\
\hline Fosfato bicálcico & 0,05 & 0,06 & 0,07 & 0,08 \\
\hline Calcário calcítico & 0,03 & 0,01 & 0,01 & 0,01 \\
\hline Suplemento vitamínico ${ }^{2}$ & 0,04 & 0,04 & 0,04 & 0,04 \\
\hline \multirow[t]{2}{*}{ Suplemento mineral ${ }^{3}$} & 0,02 & 0,02 & 0,02 & 0,02 \\
\hline & \multicolumn{4}{|c|}{ Composição químico-bromatológica (MS) } \\
\hline PB (\%) & 16,50 & 16,50 & 16,50 & 16,50 \\
\hline ELL (Mcal/kg de MS) & 1,50 & 1,51 & 1,52 & 1,52 \\
\hline Cálcio $(\%)$ & 0,53 & 0,54 & 0,57 & 0,60 \\
\hline Fósforo $(\%)$ & 0,34 & 0,34 & 0,34 & 0,34 \\
\hline
\end{tabular}

MS: matéria seca; PB: proteína bruta; ELL: energia líquida de lactação.

${ }^{1}$ Pastagem de Cynodon, predominando estrela-africana, tifton-85 e coast-cross.

${ }^{2}$ Quantidade em 1.000g = vit.A: 9.000.000UI; vit.E: $10.000 \mathrm{UI}$; vit.K3: 4g; vit.B1: 2g; vit.B2: 5g; vit.B6: 5g; vit. B12: 40mg; ac. nicotínico: 40g; ác. pantotênico: 25g; bacitracina de zinco: $10 \mathrm{~g}$; antioxidante: $30 \mathrm{~g}$; selenito: $50 \mathrm{~g}$.

${ }^{3}$ Quantidade em 500g = ferro: 90g; cobre: $10 \mathrm{~g}$; cobalto: $2 \mathrm{~g}$; manganês: 40g; zinco: $70 \mathrm{~g}$; iodo: $2 \mathrm{~g}$.

O controle da qualidade de leite produzido foi realizado do oitavo ao $21^{\circ}$ dia de cada período experimental. No oitavo e $10^{\circ}$ dias do período experimental, foram tomadas amostras do leite produzido por animal, as quais foram divididas em duas alíquotas: a primeira destinou-se à análise imediata da densidade e acidez segundo a AOAC (Official..., 1984); a segunda, acondicionada em frascos de polietileno contendo o conservante bronopol (2-bromo-2nitro-1,3-propanediol), foi mantida sob 
refrigeração para posterior avaliação centesimal de componentes químicos.

As amostras de alimentos e do pasto foram analisadas quanto aos teores de matéria seca (MS), matéria mineral (MM), proteína bruta (PB) e extrato etéreo (EE), segundo Silva (1990), e da fibra em detergente neutro (FDN) e fibra em detergente ácido (FDA) segundo Van Soest et al. (1991). A composição química média da SRM e dos tratamentos é mostrada na Tab. 2.

Tabela 2. Composição química da extrusa, da silagem do terço superior de rama de mandioca (SRM) e das dietas, com base na matéria seca (MS), segundo a proporção de substituição do pasto pela silagem de rama de mandioca

\begin{tabular}{lcccccc}
\hline \multirow{2}{*}{ Item } & \multirow{2}{*}{$\begin{array}{c}\text { Extrusa }^{4} \\
\text { (pasto) }\end{array}$} & SRM & \multicolumn{4}{c}{ Proporção de substituição } \\
\cline { 5 - 7 } \cline { 5 - 6 } & 14,07 & 24,56 & 92,62 & 93,09 & 92,81 & 92,8 \\
\hline MS (\%) & 28,65 & 7,26 & 5,33 & 5,53 & 5,34 & 5,3 \\
MO (\% de MS) & 71,35 & 92,74 & 94,67 & 94,47 & 94,66 & 94,7 \\
PB (\% de MS) & 14,82 & 26,97 & 18,13 & 16,60 & 15,69 & 14,2 \\
EE (\% de MS) & 0,86 & 5,47 & 0,73 & 0,85 & 0,85 & 0,9 \\
CT $^{1}(\%$ de MS) & 55,67 & 60,29 & 75,82 & 77,02 & 78,12 & 79,5 \\
CNF $^{2}(\%$ de MS) & - & 12,59 & 22,49 & 19,64 & 21,34 & 21,2 \\
FDN(\% de MS) & 74,77 & 51,46 & 56,07 & 60,37 & 59,55 & 61,4 \\
FDNcp (\% de MS) & 55,50 & 47,70 & 53,33 & 57,38 & 56,78 & 58,4 \\
FDA (\% de MS) & 48,37 & 35,35 & 40,69 & 41,63 & 42,34 & 42,5 \\
NDN $^{3}$ & 26,5 & 52,85 & 20,41 & 24,02 & 24,64 & 26,4 \\
NDA $^{3}$ & 4,75 & 25,46 & 5,15 & 5,63 & 5,72 & 6,1 \\
\hline
\end{tabular}

MO: matéria orgânica; PB: proteína bruta; EE: extrato etéreo; CT: carboidratos totais; CNF: carboidratos não fibrosos; FDN: fibra em detergente neutro; FDA: fibra em detergente ácido; NDN: nitrogênio insolúvel em detergente neutro; nitrogênio insolúvel em detergente ácido.

${ }^{1} \mathrm{CT}=100-(\mathrm{PB}+\mathrm{EE}+\mathrm{Cinzas}) .{ }^{2} \mathrm{CNF}=\mathrm{MO}-(\mathrm{PB}+\mathrm{EE}+\mathrm{FDNcp})$.

$3 \%$ dos compostos nitrogenados totais.

${ }^{4}$ Para a coleta da extrusa utilizou-se um novilho fistulado no esôfago, de onde foram colhidos amostras da pastagem em cada período experimental. O material foi submetido à análise para determinar a composição química do material ingerido pelo animal.

No leite foram avaliados os teores de extrato seco, proteína bruta, gordura e lactose, por meio do analisador infravermelho'. A contagem de células somáticas foi realizada por um contador eletrônico ${ }^{2}$, e as análises foram descritas em Ítavo et al. (2001).

A extração da gordura total foi feita por centrifugação (1.500rpm) e para a transesterificação dos ácidos graxos foi utilizada a metodologia descrita pela ISO (Animal..., 1978) empregando-se solução de n-heptano e $\mathrm{KOH} /$ metanol. Os ésteres de ácidos graxos foram quantificados por meio da cromatografia gasosa ${ }^{3}$. A temperatura inicial da coluna foi estabelecida em $150^{\circ} \mathrm{C}$, mantida por $3 \mathrm{~min}$, atingindo a

\footnotetext{
${ }^{1}$ Bentley Instruments, Chaska, Minnesota - EUA.

${ }^{2}$ Somacount 500, Bentley Instruments, Chaska, Minnesota EUA.

${ }^{3}$ Shimadzu 14 A. Valco Instruments Co. Inc. and VICI AG, Houston, Texas - EUA.
}

temperatura de $240^{\circ} \mathrm{C}$, ao final. Desse modo, a taxa de elevação da coluna foi de $10^{\circ} \mathrm{C} / \mathrm{min}$. A quantificação dos ácidos graxos da amostra foi feita mediante comparação dos tempos de retenção de padrões sigma, e as concentrações por meio de cálculo da área dos picos, com integrador-processador CG-300, metodologia descrita por ISO (International ..., 1978).

O experimento foi realizado segundo delineamento em quadrados latino duplo, balanceado para efeito residual de tratamentos (Lucas, 1957), segundo o modelo:

$\mathrm{Y}_{\mathrm{ijkl}}=\mu+\mathrm{Q}_{\mathrm{i}}+\mathrm{T}_{\mathrm{j}}+\mathrm{P}_{\mathrm{k}}+\mathrm{A}_{(\mathrm{i}) 1}+\mathrm{e}_{\mathrm{ijk},}$ em que:

$\mu=$ constante geral;

$\mathrm{Q}_{\mathrm{i}}=$ efeito do quadrado latino; sendo $\mathrm{i}=1$ e 2;

$\mathrm{T}_{\mathrm{j}}=$ efeito do tratamento ou nível de substituição $\mathrm{j}$, sendo $\mathrm{j}=1,2,3$ e 4 ;

$\mathrm{P}_{\mathrm{k}}=$ efeito do período experimental $\mathrm{k}$, sendo $\mathrm{k}=1$, 2,3 e 4 ; 
$\mathrm{A}_{(\mathrm{i}) 1}=$ efeito do animal ou sequência de tratamento 1, aninhada ao efeito de quadrado latino, e

$\mathrm{e}_{\mathrm{ijk}}=$ erro experimental, associado a cada observação, pressuposto $\operatorname{NID}\left(0, \sigma^{2}\right)$.

As comparações entre tratamentos foram realizadas por intermédio da decomposição da soma de quadrados relacionada a essa fonte em contrastes ortogonais relativos aos efeitos de ordem linear, quadrática e cúbica (Campos, 1984), com subsequente ajustamento de equações de regressão linear. Os coeficientes de determinação $\left(\mathrm{r}^{2} / \mathrm{h}^{2}\right)$ foram expressos pela razão entre soma de quadrados de efeitos e soma de quadrados de tratamento. Adotou-se $\alpha=0,05$.

\section{RESULTADOS E DISCUSSÃO}

As estimativas de produção diária de leite e dos parâmetros de qualidade do leite e da gordura são apresentadas na Tab. 3.

A produção diária de leite foi influenciada de forma linear $(\mathrm{P}=0,0073)$ e negativa pela proporção de suplementação em substituição da pastagem pela SRM. O mesmo ocorreu com a produção de leite corrigida para $4 \%$ de gordura $(\mathrm{P}=0,0464)$ e para a ureia $(\mathrm{P}=0,0001)$. Os teores de gordura, proteína, lactose, sólidos totais, acidez, densidade e contagem de células somáticas não apresentaram alterações, sendo os valores médios iguais a $3,7 \%, 3,1 \%, 4,5 \%$, $12,1 \%, 1,2 \%, 1,0303$ e 435,98, respectivamente.

Tabela 3. Níveis médios descritivos de probabilidade para efeitos linear (L), quadrático (Q) e cúbico (C), e coeficiente de variação (CV - \%) para produção diária de leite (PL), produção diária de leite corrigido para 4\% de gordura (PLC), gordura, densidade, proteína, lactose, sólidos totais, acidez e contagem de células somáticas (CCS) segundo a proporção de substituição do pasto pela silagem de rama de mandioca

\begin{tabular}{|c|c|c|c|c|c|c|c|c|}
\hline \multirow{2}{*}{ Item } & \multicolumn{4}{|c|}{ Proporção de substituição } & \multicolumn{3}{|c|}{ Valor de P } & \multirow{2}{*}{$\begin{array}{l}\text { CV } \\
(\%)\end{array}$} \\
\hline & $0 \%$ & $20 \%$ & $40 \%$ & $60 \%$ & $\mathrm{~L}$ & Q & $\mathrm{C}$ & \\
\hline PL $(\mathrm{kg} / \mathrm{dia})^{1}$ & 20,49 & 20,14 & 19,65 & 18,90 & 0,0073 & NS & NS & 5,6 \\
\hline $\operatorname{PLC}(\mathrm{kg} / \mathrm{dia})^{2}$ & 19,78 & 19,34 & 19,01 & 18,19 & 0,0464 & NS & NS & 7,9 \\
\hline Gordura (\%) & 3,71 & 3,70 & 3,76 & 3,76 & NS & NS & NS & 7,3 \\
\hline Densidade & 1,0301 & 1,0300 & 1,0300 & 1,0301 & NS & NS & NS & 1,5 \\
\hline Proteína (\%) & 3,04 & 3,12 & 3,03 & 3,04 & NS & NS & NS & 6,2 \\
\hline Lactose (\%) & 4,50 & 4,43 & 4,58 & 4,48 & NS & NS & NS & 3,0 \\
\hline Ureia $(\mathrm{mg} / \mathrm{dL})^{3}$ & 20,18 & 18,92 & 17,27 & 14,93 & 0,0001 & NS & NS & 9,1 \\
\hline Sólidos totais (\%) & 12,07 & 12,08 & 12,13 & 12,12 & NS & NS & NS & 2,8 \\
\hline Acidez (\%) & 1,60 & 1,49 & 1,54 & 1,46 & NS & NS & NS & 7,4 \\
\hline CCS (x1000 células/mL & 433,79 & 382,36 & 416,54 & 511,21 & NS & NS & NS & 90,0 \\
\hline
\end{tabular}

$\frac{\text { de leite })}{{ }^{\mathrm{T}} \hat{\mathrm{y}}=20,59-0,02637 \mathrm{x}\left(\mathrm{r}^{2}=0,9701\right) ;{ }^{2} \hat{\mathrm{y}}=19,84-0,02538 \mathrm{x}\left(\mathrm{r}^{2}=0,9612\right) ;{ }^{3} \hat{\mathrm{y}}=20,44-0,0871 \mathrm{x}\left(\mathrm{r}^{2}=0,9808\right) \text {. NS: não }}$ significativo $(\mathrm{P}>0,05)$.

Apesar de a elevação do fornecimento da SRM ter aumentado o consumo de alimentos suplementares e total, este foi acompanhado por redução na produção total de leite, indicando que a SRM é um alimento de menor potencial para a produção de leite que a pastagem. Esse comportamento encontra suporte no argumento apresentado por Forbes (1995), o qual afirmou que inclusões acima de $30 \%$ de volumosos de baixa qualidade em rações completas podem ser compensadas por aumento na ingestão, mas não na produção. A produção de leite com os animais em pasto sem suplementação com silagem de rama de mandioca foi de 20,49 litros/vaca/dia, sem correção, e de 19,78 litros/vaca/dia para o leite corrigido a $4 \%$ de gordura. Estes resultados estão muito próximos dos 20,6 litros/vaca/dia obtidos por Vilela et al. (2007), para vacas da raça Holandesa, na fase de lactação entre 0 e 200 dias de lactação, suplementadas com $6 \mathrm{~kg}$ de concentrado/vaca/dia.

O nitrogênio $(\mathrm{N})$ do leite é composto por caseína, soro e frações de nitrogênio não-proteico (NNP). A proteína verdadeira constitui $95,1 \%$ do nitrogênio total, e a maior parte do NNP é ureia (Block, 2000). De acordo com Broderick e Clayton (1997), a concentração de ureia no leite pode ser usada para monitorar a ingestão de proteína bruta dietética, pois o excesso de $\mathrm{N}$ ingerido pode prejudicar o desempenho reprodutivo, possibilitando elevada concentração no trato urogenital. Também o consumo do excesso de PB aumenta a exigência de energia. A 
suplementação proteica representa um dos mais elevados custos da alimentação e o excesso de $\mathrm{N}$ excretado tem impacto ambiental negativo (Broderick e Clayton, 1997).

Os valores médios da ureia no leite (NUL) enquadram-se na faixa de $12-18 \mathrm{mg} / \mathrm{dL}$. Altos valores de ureia no leite sugerem excessiva suplementação de proteína, mais que a necessária (Torrent, 2000). A concentração de NUL diminuiu $(\mathrm{P}=0,0001)$ com o aumento da proporção de substituição: os valores limites foram de 20 e $15 \mathrm{mg} / \mathrm{dL}$. A diminuição dos níveis de NUL pode ser atribuída à inclusão da SRM. Esta apresenta 26,9\% de PB, 12,4\% de lignina, $2,1 \mathrm{~g} / \mathrm{kg}$ de tanino e elevada concentração de NIDN e NIDA, respectivamente, $52,8 \%$ e $25,5 \%$.

As estimativas dos ácidos graxos saturados e insaturados na gordura do leite em razão dos diferentes tratamentos encontram-se na Tab. 4. As concentrações médias de ácidos graxos saturados e insaturados no leite foram de $66,9 \%$ e $33,8 \%$, respectivamente. Não houve interferência quanto à saturação $(\mathrm{P}>0,05)$ em função da proporção de substituição. Os resultados foram mais elevados que os relatados por Santos et al. (2001), os quais encontraram valores de $51,5 \%$ e $32,8 \%$, respectivamente, para saturados e insaturados. Mazier e Jones (1997) estudaram o efeito da gordura saturada, mono e poli-insaturada sobre a síntese de colesterol no ser humano. Observaram que na dieta rica em ácidos graxos saturados os níveis de colesterol e triglicerídeos no sangue aumentavam, e na dieta rica em ácidos graxos insaturados, diminuíam. Foi observado ainda que a concentração de HDL foi mais elevada quando se forneceu dieta contendo gorduras insaturadas. A razão média entre insaturado e saturada obtida nesse experimento foi de $0,51 \%$. Os dados observados confirmam os já relatados por Parodi (1994), Griinari et al. (1998), Kelly et al. (1998) e Bauman et al. (2000), segundo os quais o fornecimento de forragem verde aumenta a proporção de insaturado, quando comparado ao suprimento com forragem conservada (Tab. 4).

Tabela 4. Valores dos ácidos graxos saturados e insaturados na gordura do leite (g/100g de gordura) segundo a proporção de substituição do pasto pela silagem de rama de mandioca

\begin{tabular}{|c|c|c|c|c|c|c|c|c|}
\hline \multirow{2}{*}{$\begin{array}{c}\text { Ácido graxo } \\
(\%)\end{array}$} & \multicolumn{4}{|c|}{ Proporção de substituição } & \multicolumn{3}{|c|}{ Valor de $\mathrm{P}$} & \multirow{2}{*}{$\begin{array}{l}\text { CV } \\
(\%)\end{array}$} \\
\hline & $0 \%$ & $20 \%$ & $40 \%$ & $60 \%$ & $\mathrm{~L}$ & $\mathrm{Q}$ & $\mathrm{C}$ & \\
\hline Saturados & 66,45 & 66,81 & 66,46 & 67,95 & NS & NS & NS & 2,7 \\
\hline Insaturados & 34,13 & 34,46 & 33,91 & 32,53 & NS & NS & NS & 5,4 \\
\hline Insaturados:Saturados & 0,51 & 0,52 & 0,51 & 0,48 & NS & NS & NS & 2,0 \\
\hline Total & 95,55 & 94,95 & 94,71 & 95,90 & NS & NS & NS & 2,4 \\
\hline
\end{tabular}

NS: Não significativo $(\mathrm{P}>0,05)$.

O perfil dos ácidos graxos pode ser visualizado na Tab. 5. Os ácidos mirístico (C14:00), palmítico (C16:00), esteárico (C18:00) e o

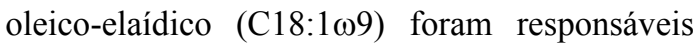
por $70,3 \%$ dos ácidos totais, cujos valores foram $9,0 \%, 27,4 \%, 13,7 \%$ e $20,3 \%$, respectivamente. $\mathrm{O}$ ácido esteárico não está associado ao colesterol, pois, ao ser ingerido, ele é metabolizado a ácido oleico. Os ácidos láurico, mirístico e palmítico são indesejáveis no leite, pois induzem ao aumento de colesterol no sangue (Griinari et al., 1996). No presente experimento, os perfis de láurico e mirístico não foram diferentes $(\mathrm{P}>0,05)$ entre os tratamentos, e o ácido palmítico aumentou linearmente com a inclusão da SRM. Dessa forma, a inclusão da SRM prejudicou a qualidade do leite.

Existe uma variação sazonal na concentração de ácidos graxos no leite e tem-se observado maior concentração de ácidos graxos insaturados durante o verão devido ao maior consumo do pasto nesta época (Reil, 1963; Parodi, 1977). Modesto (2002) forneceu SRM em substituição à silagem de milho e encontrou valores médios do ácido oleico-elaídico de 19\%. Neste experimento, também utilizando SEM em substituição ao pasto, o valor médio foi de 20,4\%. Esta observação reforça a afirmação de que o pasto apresenta maior potencial em aumentar este ácido graxo poli-insaturado quando em comparação com forragens conservadas. Por outro lado, houve aumento linear na concentração do ácido graxo gamalinolênico com o aumento da inclusão da SRM na dieta dos animais. Sendo este um ácido graxo poli-insaturado, admite-se o efeito benéfico da SRM sobre a composição do leite. 
Tabela 5. Perfil dos ácidos graxos no leite de vacas sob pastejo, segundo a proporção de substituição do pasto pela silagem de rama de mandioca

\begin{tabular}{|c|c|c|c|c|c|c|c|c|c|}
\hline \multirow[t]{2}{*}{ Nomenclatura usual } & \multirow{2}{*}{$\begin{array}{l}\mathrm{AG} \\
\mathrm{C}\end{array}$} & \multicolumn{4}{|c|}{$\begin{array}{c}\text { Proporção de substituição } \\
\text { (g/100 g do total de ácidos graxos) }\end{array}$} & \multicolumn{3}{|c|}{ Valor de P } & \multirow[t]{2}{*}{$\begin{array}{l}\mathrm{CV} \\
(\%)\end{array}$} \\
\hline & & $0 \%$ & $20 \%$ & $40 \%$ & $60 \%$ & $\mathrm{~L}$ & $\mathrm{Q}$ & $\mathrm{C}$ & \\
\hline Ácido butírico & $04: 00$ & 3,1095 & 3,2770 & 2,9479 & 2,9581 & NS & NS & NS & 15,92 \\
\hline Ácido capróico & 06:00 & 2,4171 & 2,5306 & 2,2253 & 2,3380 & NS & NS & NS & 12,33 \\
\hline Ácido caprílico & 08:00 & 1,4331 & 1,4073 & 1,3019 & 1,3890 & NS & NS & NS & 10,31 \\
\hline Ácido cáprico & $10: 00$ & 2,8731 & 2,6589 & 2,6065 & 2,7230 & NS & NS & NS & 10,12 \\
\hline Ácido láurico & $12: 00$ & 2,6710 & 2,4546 & 2,3721 & 2,5307 & NS & NS & NS & 10,30 \\
\hline Ácido mirístico & $14: 00$ & 9,2898 & 8,7876 & 8,7801 & 9,0062 & NS & NS & NS & 7,10 \\
\hline Ácido miristoléico & $14: 1(9) \omega 5$ & 0,6597 & 0,6257 & 0,6251 & 0,6189 & NS & NS & NS & 11,25 \\
\hline Ácido pentadecílico & $15: 00$ & 0,6825 & 0,6709 & 0,7364 & 0,6575 & NS & NS & NS & 14,67 \\
\hline $\begin{array}{l}\text { cis-10- } \\
\text { pentadecanóico }\end{array}$ & $15: 1 \mathrm{n} 5$ & 1,0762 & 1,1255 & 1,1363 & 1,1326 & NS & NS & NS & 7,61 \\
\hline Ácido palmítico & $16: 00$ & 26,0715 & 26,9811 & 27,4267 & 28,9177 & 0,0002 & NS & NS & 4,48 \\
\hline Ácido palmitoléico & $16: 1(9) \omega 7$ & 1,1731 & 1,1321 & 1,1534 & 1,1480 & NS & NS & NS & 14,32 \\
\hline Ácido margárico & $17: 00$ & 0,5466 & 0,5913 & 0,5981 & 0,5570 & NS & NS & NS & 13,47 \\
\hline Ácido esteárico & $18: 00$ & 13,9721 & 13,5143 & 13,5059 & 13,6810 & NS & NS & NS & 6,91 \\
\hline $\begin{array}{l}\text { Ácido oleico- } \\
\text { elaídico }\end{array}$ & $18: \ln 9$ & 21,2987 & 20,4914 & 20,0702 & 19,5050 & 0,0305 & NS & NS & 7,68 \\
\hline Ácido vacênico & $18: \ln 7$ & 3,4735 & 3,8481 & 2,9984 & 3,3650 & NS & NS & NS & 27,71 \\
\hline Ácido elaídico & $18: \ln 5$ & 0,6256 & 0,6738 & 0,6727 & 0,6680 & NS & NS & NS & 21,54 \\
\hline Ácido linoléico & $18: 2 \mathrm{n} 6$ & 1,6905 & 1,8066 & 1,8586 & 1,7312 & NS & NS & NS & 23,18 \\
\hline Ácido linoleaídico & $18: 2 \mathrm{n} 3$ & 0,3490 & 0,3990 & 0,4622 & 0,3686 & NS & NS & NS & 28,18 \\
\hline Ácido linolênico & $18: 3 n 3$ & 0,8356 & 1,0247 & 1,2281 & 0,9833 & NS & NS & NS & 30,47 \\
\hline Ácido gama & $18: 3 n 6$ & 0,5189 & 0,5521 & 0,7279 & 0,7725 & 0,0241 & NS & NS & 37,43 \\
\hline \multicolumn{10}{|l|}{ linolênico } \\
\hline Ácido araquídico & $20: 00$ & 0,3457 & 0,4224 & 0,3040 & 0,2427 & NS & NS & NS & 71,65 \\
\hline Ácido gondóico & $20: \ln 9$ & 0,1115 & 0,2402 & 0,1834 & 0,0943 & NS & NS & NS & 99,25 \\
\hline $\begin{array}{l}\text { Ácido di-homo- } \\
\text { alfa-linolênico }\end{array}$ & $20: 3 n 3$ & 0,1059 & 0,1129 & 0,1864 & 0,0939 & NS & NS & NS & 105,06 \\
\hline Ácido araquidônico & $20: 4 n 6$ & 0,1384 & 0,1467 & 0,1758 & 0,2207 & NS & NS & NS & 73,19 \\
\hline Ácido timnodônico & $20: 5 n 3$ & 0,0740 & 0,0967 & 0,0947 & 0,0767 & NS & NS & NS & 80,22 \\
\hline $\begin{array}{l}\text { Ácido 13,16- } \\
\text { docosadienóico }\end{array}$ & $22: 2 \mathrm{n} 6$ & 0,1466 & 0,1781 & 0,1894 & 0,1713 & NS & NS & NS & 77,11 \\
\hline Ácido tricosanóico & $23: 00$ & 0,2016 & 0,1861 & 0,1589 & 0,1387 & NS & NS & NS & 67,57 \\
\hline Total & & 95,8908 & 95,9357 & 94,7264 & 96,0896 & NS & NS & NS & 2,40 \\
\hline
\end{tabular}

NS: não significativo $(\mathrm{P}>0,05)$.

\section{CONCLUSÕES}

No período do verão, a inclusão da SRM na alimentação de animais lactantes em pasto resultou em diminuição da produção de leite de forma linear e diminuiu a taxa de ureia no leite. De forma geral, a inclusão da silagem de rama de mandioca prejudicou a composição do leite em relação ao perfil de ácidos graxos.

\section{AGRADECIMENTOS}

Ao Laboratório do Programa de Análises do Rebanho Leiteiro do Paraná (PARLPR) da Associação Paranaense de Criadores de Bovinos da Raça Holandesa por terem realizado as análises do leite. Ao Centro de Tecnologia para o Gerenciamento da Pecuária de Leite -Clínica do Leite - ESALQ-USP - Piracicaba pela realização da análise de ureia no leite.

\section{REFERÊNCIAS BIBLIOGRÁFICAS}

ANIMAL and vegetable fats and oils - Preparation of methyl esters of fatty acids. Method 5509. Genebra: International Organization of Standardization, 1978. p.1-6.

BAUMAN, D.E.; BAUMGARD, L.H.; CORL, B.A et al. Biosynthesis of conjugated linoleic acid in ruminants. Proc. Am. Soc. Anim. Sci., 2000. Disponível em: <http://www.asas.org/jas/ symposia/proceedings/0937.pdf.> Acessado em: 10 dez. 2005.

BLOCK, E. Nutrição de vacas leiteiras e composição do leite. In: SIMPÓSIO INTERNACIONAL SOBRE QUALIDADE DO LEITE, 2., 2000, Curitiba. Anais... Curitiba, 2000. p.85-88.

BRODERICK, G.A.; CLAYTON, M.K. A statistical evaluation of animal and nutritional factors influencing concentrations of milk urea nitrogen. $J$. Dairy Sci., v.80, p.2964-2971, 1997. 
CAMPOS, H. Estatística aplicada à experimentação com cana-de-açúcar. Piracicaba: FEALQ, 1984. 292p.

CARVALHO, V.D.; KATO, M.S. A. Potencial de utilização da parte aérea da mandioca. Inf. Agropec., v.13, p.23-28, 1987.

EUCLIDES, V.P.B.; S'THIAGO, L.R.L.; SILVA, J.M. et al. Efeito da suplementação de rama de mandioca e grão de sorgo sobre a utilização da palha de arroz por novilhos. Pesq. Agropec. Bras., v.23, p.631-643, 1988 .

FAUSTINO, J.O;; SANTOS, G.T.; MODESTO, E.C. et al. Efeito da ensilagem do terço superior da rama de mandioca triturada ou inteira e dos tempos de armazenamento na qualidade do produto final. Acta Sci., v.25, p.403-410, 2003.

FORBES, J.M. Voluntary food intake and diet selection in farm animals. Cab International, 1995. $532 \mathrm{p}$.

GONÇALVES, G.D.; SANTOS, G.T.; CECATO, U. et al. Produção e valor nutritivo de gramíneas do gênero Cynodon em diferentes idades ao corte durante o ano. Acta Sci., v.24, p.1163-1174, 2002.

GRIINARI, J.M.; DWYER, D.A.; McGUIRE, M.A. et al. Trans-octadecenoic acids and milk fat depression in lactating dairy cows. J. Dairy Sci., v.81, p.1251-1261, 1998.

GRIINARI, J.M; DWYER, D.A.; McGUIRE, M.A. et al. Partially hydrogenated fatty acid and milk fat depression. J. Dairy Sci., v.79, suppl. 1, p.177-182, 1996.

ÍTAVO, L.C.V.; SANTOS, G.T.; TOLEDO, V.A.A. et al. Milk quality and subclinical mastitis detection through somatic cells counting. Acta Sci., v.23, p.1065-1068, 2001.

KELLY, M.L.; KOLVER, E.S.; BAUMAN, D.E. et al. Effect o $f$ intake of pasture on concentrations of conjugated linoleic acid in milk of lactatinf cows. $J$. Dairy Sci., v.81, p.1630-1636. 1998.

LUCAS, H.L. Extra-period latin-square changeover designs. J. Dairy Sci., v.40, p.225-239, 1957.

MAZIER, P.M.J.; JONES, P.J.H. Diet fat saturation and feeding state modulate rates of cholesterol synthesis in normolipidemic men. J. Nutr., v.127, p.332-330, 1997.

MEDEIROS, S.R.; GAMA, M.A.S.; LANNA, D.P. Influência da nutrição animal na qualidade do leite e de produtos lácteos. In: VILELA, D.; MARTINS C.E.; BRESSAN, M. et al. (Eds). Sustentabilidade da pecuária de leite no Brasil: qualidade e segurança alimentar. Juiz de Fora: Embrapa Gado de Leite, 2001. p.17-36.
MODESTO, E.C. Utilização de mandioca na alimentação de vacas leiteiras. 2002. 96f. Tese (Doutorado) - Universidade Estadual de Maringá, Maringá.

MODESTO, E.C.; SANTOS, G.T.; VILELA, D. et al. Caracterização químico-bromatológica da silagem do terço superior da rama de mandioca. Acta Sci., v.26, p.137-146, 2004.

NUTRIENT requirement of dairy cattle. 6.ed. Washington, DC: Academic, 1998. 157p.

OFFICIAL methods of analysis. Washington: AOAC, 1984. 1041p.

PARODI, P.W. Conjugated linoleic acid: an anticarcinogenic fatty acid present in milk. Austr. Dep. Agric. Biol., v.127, p.1055-1060, 1994.

PARODI, P.W. Conjugated octadecadienoic acids of milk fat. J. Dairy Sci., v.60, p.1550-1553, 1977.

REIL, R.R. Physic-chemical characteristics of Canadian milk fat unsaturated fatty acids. J. Dairy Sci., v.46, p.102-106, 1963.

SANTOS, G.T.; ÍTAVO, L.C.V.; MODESTO, E.C. Silagens alternativas de resíduos agro-industriais. In: SIMPÓSIO SOBRE PRODUÇÃO E UTILIZAÇÃO DE FORRAGENS CONSERVADAS, 2001, Maringá. Anais... Maringá, 2001. p.262-285b.

SILVA, D.J. Análise de alimentos: métodos químicos e biológicos. 2.ed. Viçosa: UFV, 1990. 165p.

TORRENT, J. Nitrogênio ureico no leite e qualidade do leite. In: SIMPÓSIO INTERNACIONAL SOBRE QUALIDADE DO LEITE, 2000, Curitiba. Anais... Curitiba, 2000. p.27-29.

VAN SOEST, P.J. Nutritional ecology of the ruminant. Ithaca: Comstock Publishing Associates, 1994. 476p.

VAN SOEST, P.J.; ROBERTSON, J.B.; LEWIS, B.A. Symposium: carbohydrate methodology, metabolism, and nutritional implications in dairy cattle. J. Dairy Sci., v.74, p.3583-3597, 1991.

VILELA, D.; FERREIRA, A.M.; RESENDE, J.C. et al. Efeito do concentrado no desempenho produtivo, reprodutivo e econômico de vacas da raça Holandesa em pastagem de coast-cross. Arq. Bras. Med. Vet. Zootec., v.59, p.443-450, 2007.

VILELA, D.; LIMA, J.A.; RESENDE, J.C. et al. Qualidade do leite produzido por vacas holandesas em pastagem de coast-cross suplementada com concentrado. Bol. Ind. Anim., v.62, p.221-228, 2005. 